\title{
El fortalecimiento del cuadriceps disminuye el dolor y mejora la funcionalidad articular en pacientes con sobrepeso que tienen dolor de rodilla
}

\author{
Quadriceps strengthening exercises relieves pain and and improves function in overweight people with knee pain
}

Jenkinson C y col. BMJ 2009; 339: b 3170

\section{Objetivo}

Determinar el efecto del descenso de peso, de un programa de fortalemiento del cuádriceps o de ambas intervenciones, sobre el dolor articular y la funcionalidad de la rodilla en adultos con sobrepeso y obesidad.

\section{Diseño, lugar y pacientes}

Ensayo clínico pragmático*, abierto* y con análisis por intención de tratar* $^{\star}$, realizado en cinco centros de Nottingham. Enroló 389 pacientes de más de 45 años de edad (promedio 61) con un índice de masa corporal mayor a 28 (promedio 33,6 ) con gonalgia durante la mayoría de los días del último mes.

El $16 \%$ tuvo documentación radiológica de osteoartritis tibiofemoral aislada, $10 \%$ de patelofemoral aislada y $4 \%$ de ambas. Criterios de exclusión: gonalgia consecutiva a un traumatismo reciente, prótesis de rodilla, infiltración intra-articular con corticoides en los últimos tres meses y/o alguna discapacidad mental, psiquiatrica o física (p. ej. miembro amputado, artritis reumatoide).

\section{Intervención y medición de resultados principales}

Fueron aleatorizados a cuatro grupos: 1) 122 a dieta con un déficit de $600 \mathrm{kcal} /$ día con el objetivo de disminuir 0,5 a $1 \mathrm{~kg}$ de peso por semana; 2) 82 a realizar un programa no supervisado de ejercicios (cuadro 1); 3) 109 a la dieta y al programa de ejercicios descriptos previamente; 4) 76 a recibir folletos con consejos para el manejo del dolor de rodilla (grupo control).

Cuadro 1: ejercicios para ser realizados diariamente, una a dos veces por día y durante cinco a 20 repeticiones por cada pierna, respetando cada paciente su propio ritmo.

- De flexibilidad: extender y flexionar el tobillo sentado en el piso o en la cama; flexionar la rodilla en prono (acostado boca abajo); y luego del sexto mes, realizar una flexión autoasistida en prono con las piernas cruzadas.

- De contracción sin resistencia o contra resistencia suave: sentado en piso con las dos piernas extendidas hacia el frente, con las puntas de los pies hacia el techo y una toalla enrollada debajo de las rodillas, presionarla con la rodillas contra el piso utilizando la fuerza de los muslos; en decúbito supino extender la rodilla hasta quedar el muslo a $90^{\circ}$ con el tronco; sentado en una silla, extender la rodilla en los últimos $30^{\circ}$ de su recorrido.

- De contracción contra resistencia progresiva: extender la rodilla en prono desde los $90 \circ$ con banda elástica tipo "Theraband" con incremento progresivo de la tensión cada tres meses.

- Funcionales (luego de los seis meses): levantarse de la silla, caminar y subir y bajar escalón.

A los 6, 12 y 24 meses fueron aplicados los puntajes WOMAC de dolor, funcionalidad y rigidez -estableciéndose como resultado primario una mejoría en la puntuación atribuible a la intervención de $30 \%$ o más- y el SF36 de percepción global de la salud.

\section{Resultados principales}

A las 24 semanas se observó una reducción mayor al 30\% en el puntaje de dolor en el 43\% (84/191) de los pacientes asignados a intervenciones que habían incluido un programa de ejercicios y en el $32 \%(65 / 198)$ restante, con una diferencia absoluta o beneficio atribuible de $11 \%$ (IC95\% 1,8 a 21,4; NNT: 9); y una mejoría en la funcionalidad, en la rigidez articular y en la percepción global de la salud.

\section{Conclusiones}

Un programa no supervisado de ejercicios para el fortalecimiento del músculo cuádriceps aplicado durante veinticuatro meses a pacientes con sobrepeso u obesidad y gonalgia, se asoció a una disminución significativa del dolor y a una mejora en la funcionalidad de la rodilla.

Palabras claves: dolor de rodilla, intervención dietaria, cuádriceps, ejercicios de fortalecimiento.

Keywords: knee pain, dietary intervention, quadriceps strenghtening exercise. Fuentes de financiamiento: Universidad de Nottingham, en el contexto de la Artritis Research Campaign

\section{Comentario}

Si bien el resultado primario fue evaluado a los 24 meses, se evidenció un tendencia a la mejoría a los seis meses de instituida la intervención. Destacamos que quizás por no haber contado con el suficiente poder para detectarlo o porque el fortalecimiento del cuádriceps mejora a la mayoría de los dolores de rodilla (con o sin artrosis) no se pudo detectar una respuesta diferencial en los distintos subgrupos de acuerdo a los diagnósticos radiológicos documentados. Por otro lado y dado que un subgrupo de pacientes fue reclutado mediante publicidad, que se realizaron visitas domiciliarias de refuerzo y que los participantes debían completar varios cuestionarios y enviarlos por correo, consideramos que esta población no es tan representativa de la población general como para definir a este estudio como pragmático, lo que limita su validez externa.

\section{Conclusiones de los comentadores}

Una intervención sencilla sobre el estilo de vida1 documentó aliviar una condición prevalente y discapacitante como el dolor de rodilla.

Ignacio Vicente Lago [ Servicio de Medicina Familiar y Comunitaria del Hospital Italiano de Buenos Aires; ignacio.vicente@ hospitalitaliano.org.ar ]

Sergio Terrasa [ Departamento de Salud Pública del Instituto Universitario Hospital Italiano; sergio.terrasa@ hospitalitaliano.org.ar ]

Ver glosario*

Recibido el 30/06/10 y aceptado el 12/08/10

Vicente Lago I y Terrasa S. El fortalecimiento del cuadriceps disminuye el dolor y mejora la funcionalidad articular en pacientes con sobrepeso que tienen dolor de rodilla. Evid. Actual. Práct. Ambul; 13(3):89, Jul-Set 2010. Comentado de: Jenkinson C. Effects of dietary intervention and quadriceps strengthening exercises on pain and function in overweight people with knee pain: randomised controlled trial. BMJ 2009; 339 : b 3170. PMID: 19690345. 